\title{
Attributive Words in Tourism Magazines in Australia
}

\author{
Regine Margareta \\ Universitas Negeri Surabaya \\ Surabaya, Indonesia \\ reginemargareta@mhs.unesa.ac.id
}

\author{
Lisetyo Ariyant \\ Universitas Negeri Surabaya \\ Surabaya, Indonesia \\ lisetyoariyanti@unesa.ac.id
}

\begin{abstract}
This research explains the characteristics of attributive words in morphology and shows the function of common noun for determining an attributive use in pragmatics. This research uses qualitative method taken from some descriptions in the three Western Australian magazines. It must be noted that the function of attributive words and attributions which are describing the object in the magazines can help travelers to find the exact destinations they desire to go. The result shows that the attributive word (attributive adjective, attributive adverb, and attributive verb) may be located before verb and describing the NP (noun as a subject in the sentence). There were also concluded that the attributive words in the advertisements are distinguished into three types, they are attributive combination, attributive adverbial, and no attributive word. Each of those types are explained in this article.
\end{abstract}

Keywords-attributive word; attributive use; attribution; common noun

\section{INTRODUCTION}

Tourism magazines have some necessary roles for introducing the nature beauty of certain areas. The three biggest tourism magazines explaining the beauty of Western Australia's regions are taken as first, from a personal experience of the researcher to face the real conditions of some destinations based on the descriptions in the magazines as a manual book since the researcher positioned herself as one of the tourists so the experience depends on the flow of the description from the magazines. Second, there are some different theories from the researcher's perspective that makes this case interesting. In this research, there will be some findings that prove this is why the tourism magazines are important in order to introduce the country and to gain more income from the natural attractions. Third, the issue of attributive words and attributions might be crucial in order to make tourists find their desired destinations and to avoid disappointment to the incomplete descriptions. There are two important points that must be studied further. One is the characteristics of both attributive words and attribution, and then second is the attributive use identification from the employment of common noun and proper noun. From the common noun and proper noun the researcher tries to find out the exact entity name (proper name) of the object being told. There are three types of attributive words, they are:

\section{A. Attributive adjective}

Adjective as a grammar is functioned as a classification, description, and identification for a noun. Kullenberg [4] claims that in one appearance an adjective can perform more than one role. Huddleston \& Pullum [3] state that Adjective that appears in the first place before a verb has a character as an attributive adjective. Besides, for adjective appears after a verb is called predicative adjective.

\section{B. Attributive noun:}

Attributive noun known as noun-adjunct claimed in Chicago Manual Style site describes an attributive noun contains with a noun that describe another noun (the main noun whether a noun acts as an object or subject).

\section{Attributive verb}

Hunddleston once again states that attributive verb is a verb that acts like an adjective. The role of attributive verb is to describe the main noun. The three of the type of attributive words always show before the main noun. Most commonly found with a formula $\mathrm{V}$-ing form, then to infinitive and past perfect. Applied similar to other attributive noun and attributive adjective, attributive verb comes out before a verb, typically to describe a noun as a subject.

\section{ATTRIBUTIVE USE}

\section{A. Attributive Use}

Donnellan [1] [2], a famous linguist, asserts that definite description that is uttered by a speaker is attributively portraying something about a noun to which the description fits in. Not mentioning the other aspect other than definite description to indefinite description makes this as a research gap to what will happen when an indefinite description (attribution) explains the NP.

Research questions of this research are (1) what the characteristics can be found in determining an attributive words and attribution, and (2) how the common noun uncovers the existence of a noun being described in attributive use form. The aim of this research is to reveal more detailed attributive words' form and their other components that might be helpful to improve the creation of magazines and to not mislead magazine readers with too general information owing to the use of common noun.

\section{RESEARCH METHOD}

Descriptive qualitative research method is chosen to be the method of this research since the data need an explanation in some meaning that related to the existence of an entity especially for answering the research question 2 . The focuses of this research are the components of attributive words and attributions (including the types, grammar function, location, and question words), and the use of common noun in examining 
attributive use. The data consist of sentences cut from description randomly from the pages in the magazines. The magazines were published in 2016 with titles: Australia's Coral Coast, Visit Ningaloo Exmouth \& Coral Bay, and Kimberly \& Pilbara Western Australia. The contents of these magazines are the list of the tourism places with the specific description following every places mentioned. These description of tourism places conduct attributive words in describing the details of each tourism places. The researcher is a data collector, data analyst, and experiment and correspondent of the result as the instruments of this research. The magazines only describe Western Australia's region (along the coral coast) and the North West regions of Western Australia. The data are written text, the written texts then being analyzed, categorized, interpreted, and explained. The data reduction have been done through some process like, selecting the description explanation, identifying the attributive words, analyzing the form of the attributive words.

\section{RESULTS AND DISCUSSION}

In this part, it conducts the types of attributive words, how they are positioned in tourism magazines, and how common noun exposes the existence of a noun. The following scheme explain how the attributive words are conducted in the description of tourism places in the magazines.

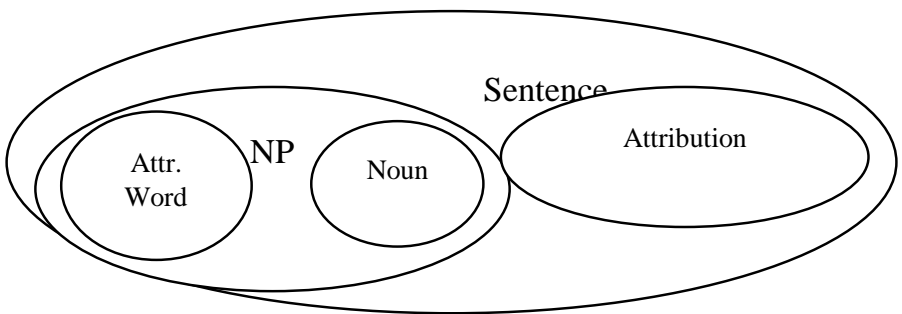

Fig. 1. The basic concept scheme of attributive words in describing an object

\section{Attributive words in the magazines}

\section{A. Data 1}

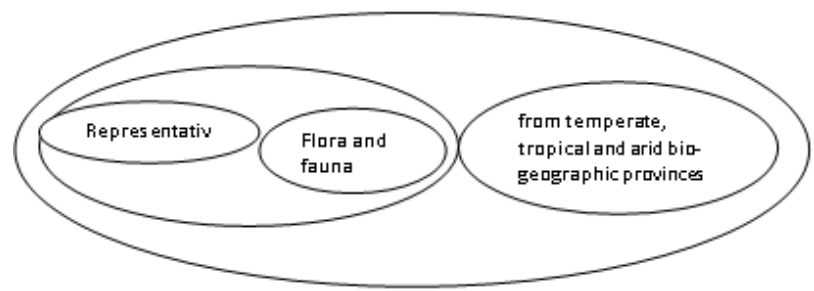

Fig. 2. The concept scheme of of attributive words in describing 'Flora and Fauna'
TABLE 1. THE 'FLORA AND FAUNA' ANALYSIS

\begin{tabular}{|l|l|l|}
\hline Sentence & NP & Attribution \\
\hline $\begin{array}{l}\text { The Cape Range National } \\
\text { Park is of a high } \\
\text { conservation value and } \\
\text { biologically rich with } \\
\text { representative flora and } \\
\text { fauna from temperate, } \\
\text { tropical and arid bio- } \\
\underline{\text { geographic provinces }}\end{array}$ & $\begin{array}{l}\text { representative } \\
\text { flora and } \\
\text { fauna }\end{array}$ & $\begin{array}{l}\text { from } \\
\text { temperate, } \\
\text { tropical } \\
\text { and arid } \\
\text { bio- } \\
\text { geographic } \\
\text { provinces }\end{array}$ \\
\hline
\end{tabular}

The NPs are representative flora and fauna. To make it single then they can be split as "representative flora" and "representative fauna". The focus of the attributive word is on the word representative acts as an adjective. These NP have no article. Thus, this article is an attributive adjective. The attribution of this datum starts with a word from that is a proposition, placed at the end of the sentence and answers the question what, explaining the flora's and fauna's conditions.

\section{B. Data 2}

TABLE 2. 'THE LOCAL EMUS' ANALYSIS

\begin{tabular}{|l|l|l|}
\hline Sentence & NP & Attribution \\
\hline $\begin{array}{l}\text { Observe the local emus } \\
\text { stopping traffic on Exmouth's } \\
\text { main street; }\end{array}$ & $\begin{array}{l}\text { the } \\
\text { local } \\
\text { emus }\end{array}$ & $\begin{array}{l}\text { stopping traffic on } \\
\text { Exmouth's main } \\
\text { street }\end{array}$ \\
\hline
\end{tabular}

The local emus is the NP, where it has article the as a definite article. The word local is a noun, means this sentence is an attributive noun. This is a referential use because the NP the local emus to be believe that there is only one species of emu all around the world, so this is obvious that all emus look exactly the same (all people have known this). Also, this animal has no wider categorization. When this emus word is compared to wildflowers, readers assume they have already known emus only one animal, do not represent other species in anyway, on the other hand, wildflowers represents other species. The best question for the attribution where to show the place where travelers can look at wild emus. The attribution, starts with a gerund as a verb stopping, is placed in the centre of the sentence. The best question for the attribution where to show the place where travelers can look at wild emus.

\section{Data 3}

TABLE 3. 'A WINDSURFING AND SAILING HUB' ANALYSIS

\begin{tabular}{|l|l|l|}
\hline Sentence & NP & Attribution \\
\hline $\begin{array}{l}\text { Leeman is a windsurfing and } \\
\text { sailing hub with consistent } \\
\text { strong summer winds } \\
\text { providing excellent conditions }\end{array}$ & $\begin{array}{l}\text { windsurfing and } \\
\text { sailing hub }\end{array}$ & $\begin{array}{l}\text { with consistent } \\
\text { strong summer } \\
\text { winds }\end{array}$ \\
& & \\
\hline
\end{tabular}


The NP is a windsurfing and sailing hub. The main noun is hub. This is an indefinite NP since a appears as the article. The attributive words are windsurfing and sailing which look like verbs but the actual act is adjectives. The initial of this attribution is with that also is a preposition. The attributive words come right after a linkin verb is and placed in the centre of the sentence. The attribution indicates what, condition of the hub.

\section{Data 4}

TABLE 4. 'FIVE WORLD HERITAGE' ANALYSIS

\begin{tabular}{|l|l|l|}
\hline Sentence & NP & Attribution \\
\hline $\begin{array}{l}\text { The drive crosses the Northern } \\
\text { Territory and passes through five } \\
\text { World Heritage listed areas, } \\
\text { offering some of the most }\end{array}$ & $\begin{array}{l}\text { five World } \\
\text { Heritage }\end{array}$ & $\begin{array}{l}\text { offering some } \\
\text { of the most } \\
\text { spectacular } \\
\text { sights in } \\
\text { spectacular sights in northern }\end{array}$ \\
Australia & & $\begin{array}{l}\text { northern } \\
\text { Australia }\end{array}$ \\
\hline
\end{tabular}

The NP of this datum is five World Heritage where there is no article, so the NP is a nude. The words five and World that come before the main noun Heritage act as noun (five) represents the amount of the noun and adjective (World). The attributives of the NP are attributive noun and attributive adjective. The initial of the attribution starts with gerund as a verb, offering. Though, the words that split the NP from the attribution mention areas but it does not mean that the question of the attribution is where (asking place), instead the question is what, pointing out sights in northern Australia. The attribution also appears at the end of the sentence.

\section{E. Data 5}

TABLE 5. 'THE TOP OF MOUNT LESUER' ANALYSIS

\begin{tabular}{|l|l|l|}
\hline Sentence & NP & Attribution \\
\hline $\begin{array}{l}\text { Drive to the top of Mount } \\
\begin{array}{l}\text { Lesuer for a magnificent } \\
\text { panoramic view of the park and } \\
\text { coast line }\end{array}\end{array}$ & $\begin{array}{l}\text { the top of } \\
\text { Lesuer }\end{array}$ & $\begin{array}{l}\text { for a magnificent } \\
\text { panoramic view of the } \\
\text { park and coast line }\end{array}$ \\
\hline
\end{tabular}

The NP is the top of Mount Lesuer. The Initial word of this NP is Mount Lesuer. This NP uses the as definite clause. The indication of attributive word comes to the top of as prepositional phrase or more widely common as adverbial. So, the datum uses attributive adverbial, which has not been included in the previous theory. The initial Attribution of this datum is for, functioned as preposition. The condition of this attribution emphasizes a question what for informing the view of Mount Lesuer.

\section{F. Data 6}

TABLE 6. 'A BROCHURE' ANALYSIS

\begin{tabular}{|l|l|l|}
\hline Sentence & NP & Attribution \\
\hline $\begin{array}{l}\text { Pick up a brochure detailing } \\
\text { scenic driving routes from the }\end{array}$ & a brochure & $\begin{array}{l}\text { detailing scenic driving } \\
\text { routes from the } \\
\text { Mullewa Community Resource }\end{array}$ \\
$\underline{\text { Centre }}$ & & $\begin{array}{l}\text { Mullewa Community } \\
\text { Resource Centre }\end{array}$ \\
\hline
\end{tabular}

This is not a full-sentence. The NP is a brochure. Even though there is no other addition for attributive word indicating the NP. So far, this datum has an indefinite article a. Since a brochure is the main noun stand alone, so there is no attributive word. The NP and its attribution show at the end of the sentence, as stated before that this whole sentence is more like a command or suggestion not a statement that need a subject, verb, and object. The attribution starts with a gerund acts as a verb with the word detailing. The attribution indicates where question explaining the scenic driving routes.

Common Noun Revealing the Entity in Attributive Use's Description

This section tells the other name that can replace common noun and explains the reason of a NP using attributive use.

\section{A. Data 1 : representative flora and fauna}

Flora and fauna are common nouns. This issue is similar to wildflowers that the writers do not give the proper noun of the varieties. The reason for the same case is obvious that there are a lot of names to be mentioned, and the spaces are needed to describe other more important things than calling the names. This sentence utilizes attributive use since not all tourism magazines show endemic fauna. From five magazines even the two are not included in this thesis only one magazine shows a map of endemic fauna along West Coast. If the readers do not read that one magazine, the readers might only end up knowing kangaroo, emu, and koala as the endemic fauna in Australia, but other smaller areas have their own endemic fauna too.

Whether or not that the fauna (rarely mentioned) is as important as places. Meeting with endemic creatures must be interesting, but does not matter if writers think this is less important than the rest.

\section{B. Data 2: The local emus}

Even though the NP uses common noun for referential use, but in fact there is only one species of emu that can be found in Australia. Especially for creature except using proper noun for Latin name as (emus) Dromaiidae, (ostriches) Struthionidae, (rheas) Rheidae, (kiwi) Apterygidae, etc. the use of common noun for emus only points on one entity.

\section{Data 3: a windsurfing and sailing hub}

It is obvious that the NP is indefinite where it is freshly introduced with an article a, the whole words are common noun. In fact, the readers (for example: I) I do not know whether there is only one hub in Leeman or there is another. In case if there are more than one hub, so which hub is described by the sentence? It is stated that Leeman itself is the hub, however Leeman is a name of a small coastal town with both side (west and east border ocean and sea). The location of the windsurfing and sailing hub is unknown, but is claimed to exist. The NP a windsurfing and sailing hub has attributed Leeman, and strengthen by the attribution with consistent strong summer winds. Pay attention to the words consistent and strong for they are attributing the NP plus Leeman. The assumption, this sentence is put inside a magazine is to highlight the advantage for surfer and sailor to use the opportunity while visiting Leeman. 
This sentence applies attributive use because travelers do not know where the right point of the hub is if they do not put a map on. Another question is if Leeman has more than one hub then why the writers of the magazine do not put proper name of the hub, instead of hanging travelers with questions? From the findings, there is no exact place even in a digital map that shows where the hub is. Therefore, even if the hub exists the writers are also a human that has limited knowledge too, or simply the hub does not have a name.

\section{Data 4: five World Heritage}

The NP is a proper name. Five as a common noun, and World Heritage as a proper name for a reason that the two words use capital. Although, this is commonly found, readers probably should know the specification of in what kind the areas become the heritage. The NP in real life is used as a title to label something. The attribution that explains NP from the phrase the most spectacular sights in northern Australia. The label itself is very important that shows the value of the areas listed. That is why the writers of the magazine include this label/title to show the prominent parts inside the description.

Since there are five World Heritage in the areas listed but do not introduced by the writers, readers assume that those places exist but have to guess where they are located or have to find out more by searching on internet or reading books that can explain the existence of the areas. This is why the sentence implies attributive use. This must sound interesting and challenging for.

\section{E. Data 5: the top of Mount Lesuer}

Mount Lesuer is a proper name, contains with Mount (common noun) and Lesuer (proper name). The focus is the top of where the NP has already claimed to be a proper name which means it exactly exists and there is one and only entity to be pointed at. It is true that the initial letter for both words begin with capital letters as well.

The search on Google catches that the exact place (Mount Lesuer) is 21 kilometers from Jurien Bay in Western Australia The travelers who want to reach this place are able to find this place easily, however this little information is important for travelers.

This sentence employs an attributive use if and only if the readers believe this place indeed exist (because proper names are absolutely existed entities) yet do not know this place in real, so a searching might help them.

Mount Lesuer must be a great nature attraction. However, for a new travelers, they must not know from what point is the best to see the whole magnificent view. This is the reason why the attribution focuses on the view than any other description.

\section{F. Data 6: a brochure}

A brochure consists of two common noun and an indefinite. This leaves traveler's wonder where to get the brochure. Talking about routes, this is the most important information to take a journey for travelers in order to not get lost. What in mind is if travelers have to know the routes out from Mullewa, the travelers must visit the Mullewa Community Resource Centre which may provide or sell souvenirs. Besides giving information for travelers, tourism magazines can promote for benefits. This sentence utilizes attributive use since if the NP stands alone the travelers will not know which brochure to get from the Mullewa Community Resource Centre. There must be more than 10 brochure provided in the Resource Centre, the attribution makes the intention of the magazine's writer clearer to take brochure which explains the routes to wherever the travelers want to continue their journey after visiting the Mullewa Community Resource Centre.

From the analysis above, there are several significant points that needed to be drawn. Based on the theory, three kinds of attributive word, it is true that the attributive word (attributive adjective, attributive adverb, and attributive verb) appears at before verb and describing the NP (noun as a subject in the sentence). The attributive words appear to be short and simple means the description that the attributive portrays is small. Compared to the attribution that has its own location in the sentence as well as its own question word that determines what kind of description the attribution stands for.

There are other kinds of attributive words: attributive combination, attributive adverbial, and no attributive word. The attributive combination can be a combination of noun and adjective, noun and verb, or noun and adverbial. The attributive adverbial actually is a piece of preposition phrase (grammar function), do not forget that some PP (prep. phrase) can turn into adverbial in some cases. Then, the reason of eliminating attributive and attribution is based on this 'no attributive word'.

Furthermore, the attribution is longer than the attributive words and most of the attributions appear to be following the verb. The attribution is much longer than the attributive words means that the attributions detail the NP deeper than the attributive word (the scale of the readers interpretation is more narrow). In fact, the attribution gives better view than the attributive words. However, when both attributive words and attributions are eliminated there will be no alteration towards the NP even it also denotes that readers might find it even more difficult to find the location. The initial of attribution vary from most commonly found preposition and gerund, the other grammar function might also appear in a rare different occasion.

When using an attributive use as Donnellan claims, to whatever fits the description after a NP is described by the attribution, the NP might show some faces. Revealing the entity of NP (since the NP employs attributive use), readers need to merge the attributive words, the NP, and the attribution together and find the "whatever-fits" as described. Some of the common nouns cannot be identified as their replacement of proper noun, however when the data analyzed the purposes of writers to put the sentences as they are is first, the replacement of common nouns might take too much space that the magazines should inform other details that are more important than the replacements of common noun in NP. Second, if the common noun has to be replaced by the proper noun, there is a possibility that actually the writers have not visited the destinations described yet so that they use common noun to tell the readers the common things that the readers might find and what is generally different from other places. The last, as an advertisement sometimes writers want to make things simple, common nouns will make readers wonder more by not telling the whole details. Then, the reason for easily finding these 
attributive words and attributions in tourism magazines are to inform, to show, and to lead people to the exact destination that will not make readers (tourists) misled.

\section{CONCLUSION}

There are other kinds of attributive words that are attributive combination showing words that appear before a verb explaining the NP but have two different grammar functions, attributive adverbial that has a grammar function as a PP but can change to adverbial in some cases, and no attributive word where the NP usually only consists of a noun or a noun with an article or determiner. The attributive words describe the NP in a small scale moreover; attributions describe the NP in a bigger scale. The attributions have their own unique pattern of initial (grammar function) to determine the easiest way to indicate that they are an attribution. Most attribution starts with gerund or preposition especially when the attribution directly follows the $\mathrm{NP}$, in a rare case when the attributions are separated from the subject NP the grammar function of attribution changes.

The elimination of attributive words and attributions will not affect much to the NP but the NP will be more difficult to be recognized. The common nouns have a relation behind the employment of attributive use (in pragmatics) and also the common nouns tell the purpose of the writers in creating the magazines' articles [5]. The implication of these attributive words in these tourism magazines covers three things. Firstly, it can help the tourist to find the exact tourism destination. Secondly, it definitely gives an attractive tempting invitation for the tourist to visit those tourism places, in this way the (regional) government can have a lot of profit from the visitors. Thirdly, these attributive words in the magazines can help the tourists not to mislead to the wrong area because they also provide the details area of the tourism places.

So far this research combines pragmatics and morphology. If the grammar function really matters for any cases that have not been explained in this study then it will be good to see what the structure of the grammar influence the NP of any object or subject that is being exposed. It is because most of the NP is positioned as a subject in the sentence there might be a possibility for attributive words come before NP as an object even it will be so rare but it can be evolved. Since common noun has a relation with the employment of attributive use instead of only the definite or indefinite description. Donnellan claims then there must be some other aspects as well that have not been found to have a relation with the employment of attributive use.

\section{REFERENCES}

[1] K. S. Donnellan, "Reference and Definite Descriptions," The Philosophical Review, vol.75(3), pp. 281, 1996. [Online] Available: Doi:10.23/2183143

[2] K. S. Donnellan, "Reference and definite descriptions," Philosophical Review, vol. 75, pp. 281- 304, 1996.

[3] R. Huddleston, Introduction to the Grammar of English, Cambridge University Press, pp. 100, 1984.

[4] H. Kullenberg, Function of Attributive Adjectives in English.

[5] G. Yule, Pragmatics. Oxford, Oxford University Press, 1996. 